\title{
Knowledge and Perspectives of Postgraduate Nurses regarding compe- tency of Advanced Nursing Practice in Kurdistan Region of Iraq
}

Bootan Hasan Ahmed ; Department of Nursing, College of Nursing, Hawler Medical University, Erbil, Iraq.

Ribwar Arsalan Mohammed; Department of Nursing, College of Nursing, University of Raparin, Sulaimaniya , Iraq.

Sanaa Hassan Abdulsahib ; Department of Nursing, College of Nursing, University of Raparin .Sulaimaniya , Iraq.

Vian Afan Naqshbandi; Department of Nursing, College of Nursing, Hawler Medical University, Erbil, Iraq.

(Correspondence: ribwar@uor.edu.krd)

\section{ABSTRACT}

Background and objectives: Advanced nursing practice (ANP) involves integration role domains, which are related to clinical practice, education, research, professional development and organizational leadership. The objectives of this study were to assess the knowledge and perspective of graduated nurse regarding competency of advanced nursing practice and explain the domains of advanced nursing practice competency.

Methods: This cross-sectional study sought to determine knowledge and perspective of graduated nurses regarding advanced nursing practice in Kurdistan region from $20^{\text {th }}$ June 2014 to $20^{\text {th }}$ December 2014. Nurses who held degrees including Master of Science, and Philosophy of Doctorate or both were invited to participate. One hundred and fifty participants met the inclusion criteria, and 50 completely responded to the questionnaire. Data were analyzed by using Statistical Package for the Social Sciences (SPSS) Version (20). Results: The total 50 of interviewed participants responded to the survey, with 24 (48\%) considering that an ANP should have autonomy in clinical practice. While 28 (56\%) and 35 (70 \%) of participants mentioned that an ANP should be able to manage complexity throughout clinical placement.

Conclusion: Considerable number of participants in this study did not have adequate and satisfactory knowledge regarding advanced nursing practice.

Keywords: Advanced nursing practice, Knowledge, Nurse.

\section{INTRODUCTION}

Advanced nursing practice (ANP) is a high degree of knowledge, skill and experience that is applied within the nurse-consumer relationship to achieve optimal outcomes through critical analysis, problem solving and accurate decision-making [1]. ANP has always existed because nursing is continually evolving, and this might be reflecting on patients and community service needs [2]. Besides, the role of the advanced nurse has grown continuously over the last centuries due to pressures related to reimbursement and managed care, a growing patient advocacy, and changing attitudes about role of nurses. 
As a result, these phenomena were helpful in developing role of nurse [3].

Studies have demonstrated that many reasons and events that are helpful in emerging and developing role of ANP but are not limited including the health care needs of the population, practice pattern and new models of care, education, workforce issues and the legacy and policy context [12]. Similarly, another study introduces that socio-political environment, government policy and support, intra/ inter professional collaboration and developing nursing education shaped ANP [4,5]. Furthermore, health cares policy and culture of the health care settings where nurse work played a considerable role in shaping and defining role of ANP [10].

The concept of advanced nursing practice (ANP) and/or advanced practice nurse (APN) have been used interchangeably among the literature and studies; however, they represent the same meaning $[4,6,12$, 13]. There is no single definition of ANP but there is a consensus agreement that it extends traditional scope of nursing, highly autonomous practice of nurse, increase the use of nursing knowledge and participating to the development of profession [14, 15]

APN has been defined in different forms in studies. For example, International Council of Nurses (ICN) defines ANP as a "registered nurse who has acquired the expert knowledge base, complex decision making skills and clinical competencies for expanded practice the characteristics for which are shaped by the context and / or country in which $s /$ he credentialed to practice. A master's degree is required for entry level" [7]. Thus, there is lack of worldwide acceptance regarding the definition of ANP and this led to inconsistency about competencies that are required for this level of practice $[11,18]$. However, there are three features that distinguishes APN from basic nursing practice including specialization of care for a specific population of patient with complex health care needs, acquisition of recent knowledge and skills as well as autonomy extending in scope of nursing practice $[14,15]$

Competence and skills are required to achieve ANP but describing these two terminologies is complex and dynamic [10, 13]. Competency is a quality or characteristics of a person that is related to effective performance including combination of knowledge, skills, motives and traits [19]. On the other hand, ICN defines competency as the level of performance demonstrating the effective application of knowledge, skills, judgment and personal attributes required to practice safely and ethically in a diagnosed role and setting [7]. Distinguishing the role of APN is less difficult in countries including the United States, where legalization, regulatory mechanisms, protected titles for clinical nurse specialist, nurse midwives, nurse anesthetists and nurse practitioners exist [10]. Because problems might arise when several roles are applied to the same title, such as nurse specialist, there is now an international agreement about the utilization of titles to distinguish the ANP role. Bryant-Lukosius and DiCenso (2004) stated that roles of ANP would be clearly distinguished due to lack of regulation and protective title for nurses in clinical nurse specialist. The role is defined as the competences related to clinical practice, education, research, organizational leadership, and professional development [10]. In the Kurdistan Region (KR) of Iraq, the College of Nursing was created in three provinces including Erbil, Sulimani, Dohuk and Raparin in 2001 in order to develop the nurse workforce. Increasing the number of undergraduate students, developing higher education 
degrees (Master, and $\mathrm{PhD}$ ) in nursing fields, increasing workload on the physicians, and developing more subspecialties in clinical practice demonstrate ANP in nursing education in the KR. This I because when health care delivery increases via consumer demands, ANP may emerge [4].

Surprisingly, in $K R$, there is no a scientific evidence regarding the perspective of graduated nurses on ANP at nursing academic institutions. ANP in academic settings are introduced to change pattern of practice, identification of skills and specialization in a relevant field [20]. As health-care is always evolving, innovative clinical practitioner is required in order to play a major role in health care settings [14].

The primary aim of this article is to assess the knowledge of graduate nurses regarding competence of ANP and to examine their perspectives toward incorporation of ANP in Kurdistan Region health care facilities.

\section{METHODS}

A quantitative cross-sectional study was carried out to assess knowledge and perspective of graduated nurses regarding competency of ANP in Kurdistan region of Iraq from June 20, 2014 to December 20, 2014.

Following an extensive reading of ANP literature, and specifically advanced nursing practice toolkit [21] a constructed questionnaire was developed to meet the purpose of the study. It was reviewed by two expertise's in order to improve internal validity and internal consistency reliability of the questionnaire. The questionnaire was composed of three sections. The first section was demographical characteristics of participants. The second section was composed of knowledge regarding competencies of ANP. The third section was the perspective of participants regarding developing ANP in KR. The questionnaire was given to participants to complete individually.

Eligible criteria to participate in this study were nurses who were holding Master of Science in Nursing (M.Sc.), Philosophy of Doctorate $(\mathrm{PhD})$ or both; having a scientific degree that is not less than assistant lecturer and being able to speak and write in English. Both Diploma and M.Sc. degree considered studying of graduate for 2 years separately, whereas PhD degree was considered studying of graduate degree for three to four years.

Participants were attending schools of nursing in public universities including Hawler Medical University, University of Raparin, Duhok University, public and private hospitals. Prior to commencement of the study, written confirmation was obtained from Research Committee in College of Nursing in Hawler Medical University. A total 150 participants met the inclusion criteria. Data collection was done by self-administered questionnaire, and given to the participants in the given areas, and only 50 completely responded questions in the questionnaire; the remaining rejected to participate in the study.

Data were analyzed by using Statistical Package for the Social Sciences (SPSS) Version (20). In which mean and standard deviation of participants were taken in terms of age and their experience as a nurse. Then, frequency and percentage of participants with respect to each question was introduced.

\section{RESULTS}

Regarding demographical data, Mean and Standard Deviation of the participant age 
and years of experience in nursing were $40.08 \pm 9.52$ and $6.58 \pm 4.46$ respectively.

The majority of participants were studying inside of Iraqi universities (78\%), whereas $22 \%$ of them were finished the postgraduate degree abroad. Most held a Masters degree (68\%). The academic titles of the participants were mainly assistant lecturer (48\%), while lecturer, assistant professor and professor were 28\%, $12 \%$ and $2 \%$ respectively as revealed in the table 1.

Table 1: Participant Characteristics

\begin{tabular}{|c|c|c|c|}
\hline \multicolumn{2}{|c|}{ Participant characteristics } & \multirow{2}{*}{$\begin{array}{c}\text { Frequency } \\
40\end{array}$} & \multirow{2}{*}{$\begin{array}{l}\% \\
80\end{array}$} \\
\hline \multirow{5}{*}{ Roles } & Educator and & & \\
\hline & Researcher & & \\
\hline & Leader & 5 & 10 \\
\hline & Clinical & 5 & 10 \\
\hline & Practitioner & & \\
\hline & Total & 50 & 100 \\
\hline \multirow{6}{*}{$\begin{array}{l}\text { Academic } \\
\text { title }\end{array}$} & Assistant lecturer & 24 & 48 \\
\hline & Lecturer & 14 & 28 \\
\hline & Assistant & 6 & 12 \\
\hline & Professor & & \\
\hline & Professor & 1 & 2 \\
\hline & $\begin{array}{c}\text { No academic } \\
\text { title }\end{array}$ & 5 & 10 \\
\hline \multirow{4}{*}{ Qualification } & Total & 50 & 100 \\
\hline & MSc & 34 & 68 \\
\hline & $\mathrm{PhD}$ & 16 & 32 \\
\hline & Total & 50 & 100 \\
\hline
\end{tabular}

Regarding the prerequisite qualification to take ANP role, $22 \%$ of participants thought that holding a diploma was a minimum requirement, compared to $20 \%$ who believed that holding a Masters degree was required. The majority believed that ANP must be an advanced clinical practitioner $(76 \%)$, whereas only $4 \%$ of them highlighted that an ANP should play all roles. (Table 2 ).
Table 2: Knowledge of participants regarding, pre-requisites qualification and roles of advanced nursing practice

\begin{tabular}{|c|c|c|c|}
\hline \multirow{2}{*}{$\begin{array}{l}\text { Pre- } \\
\text { requisite }\end{array}$} & & $\begin{array}{c}\text { Frequen- } \\
\text { cy }\end{array}$ & $\%$ \\
\hline & CBTC & 10 & 20 \\
\hline qualifica- & Diploma & 11 & 22 \\
\hline tion & BSC & 10 & 20 \\
\hline \multirow{2}{*}{ of ANP } & MSc & 10 & 20 \\
\hline & $\mathrm{PhD}$ & 9 & 18 \\
\hline \multicolumn{2}{|c|}{ Total } & 50 & 100 \\
\hline \multirow{8}{*}{ ANP roles } & $\begin{array}{l}\text { Clinical/ } \\
\text { Professional } \\
\text { Leadership }\end{array}$ & 4 & 8.0 \\
\hline & $\begin{array}{l}\text { Facilitating } \\
\text { Learning }\end{array}$ & 5 & 10.0 \\
\hline & $\begin{array}{l}\text { Research } \\
\text { and } \\
\text { Develop- } \\
\text { ment }\end{array}$ & 1 & 2.0 \\
\hline & Advanced & 38 & 76.0 \\
\hline & Clinical & & \\
\hline & Practice & & \\
\hline & All above & 2 & 4.0 \\
\hline & otal & 50 & 100.0 \\
\hline
\end{tabular}

Table 3 reveals that almost all participants (86\%) posited that decision-making, clinical judgment and problem solving are the main competencies that an advanced clinical practitioner must have, during their clinical practice. On the other hand, 24 (48 $\%)$ and 21 (42\%) considered that an ANP should have autonomy in clinical practice and managing risk respectively. While 28 (56 \%) and 35 (70\%) of participants mentioned that an ANP should be able to manage complexity and have a good communication skill with colleagues throughout clinical placement respectively.

Table 4 shows number of participants believed that an ANP should develop their ability to access research 17 (34\%) and implement research findings 17 (34\%) in clinical placement. However, low number of participants suggested that ANP need to 
develop their ability in terms of presenting seminar in conference $14(28 \%)$ and publication 12 (24\%)

Table 3: Perspectives of participants regarding skill abilities and characteristics of advanced clinical Practice

\begin{tabular}{|c|c|c|}
\hline $\begin{array}{c}\text { Advanced Clinical } \\
\text { Practice }\end{array}$ & Frequency & $\%$ \\
\hline $\begin{array}{l}\text { Decision making / clinical } \\
\text { judgment and problem }\end{array}$ & 43 & 86 \\
\hline $\begin{array}{l}\text { solving } \\
\text { Critical thinking and } \\
\text { analytical skills } \\
\text { incorporating critical } \\
\text { reflection }\end{array}$ & 35 & 70 \\
\hline Managing complexity & 28 & 56 \\
\hline $\begin{array}{l}\text { Assessment, diagnosis } \\
\text { referral, discharge }\end{array}$ & 34 & 68 \\
\hline $\begin{array}{l}\text { Developing higher levels } \\
\text { of autonomy }\end{array}$ & 24 & 48 \\
\hline $\begin{array}{l}\text { Assessing and } \\
\text { managing risk }\end{array}$ & 21 & 42 \\
\hline Prescribing & 25 & 50 \\
\hline Developing confidence & 29 & 58 \\
\hline $\begin{array}{l}\text { Developing therapeutic } \\
\text { nursing to improve patient } \\
\text { outcomes }\end{array}$ & 33 & 66 \\
\hline $\begin{array}{l}\text { Higher level } \\
\text { communication skills }\end{array}$ & 35 & 70 \\
\hline $\begin{array}{l}\text { Patient Focus / Public } \\
\text { Involvement }\end{array}$ & 31 & 62 \\
\hline
\end{tabular}
centers and hospitals in KR. Besides, 23 (46 health care needs of society, while 3(6\%)

Table 4: Perspective of participants regarding research, and development competency domains of advanced nursing practice

\begin{tabular}{|c|c|c|}
\hline Research and Development & $\begin{array}{c}\text { Frequen- } \\
\text { cy }\end{array}$ & $\begin{array}{l}\text { Per- } \\
\text { cent \% }\end{array}$ \\
\hline $\begin{array}{l}\text { Ability to access research/ } \\
\text { use information }\end{array}$ & 17 & 34 \\
\hline $\begin{array}{l}\text { Critical appraisal / } \\
\text { evaluation skills }\end{array}$ & 14 & 28 \\
\hline $\begin{array}{l}\text { Involvement in research / } \\
\text { audit }\end{array}$ & 13 & 26 \\
\hline Ability to implement & 17 & 34 \\
\hline research findings into & & \\
\hline practice- including use of & & \\
\hline and development of & & \\
\hline policies / protocols and & & \\
\hline guidelines. & & \\
\hline Conference presentations & 14 & 28 \\
\hline Publications & 12 & 24 \\
\hline
\end{tabular}

Table 5 reveals that participants supposed that being able to learn and improve nurse's capability and building capacity 17 (34 \%). However, 10 (20\%) and 14 (28\%) of participants demonstrated that an ANP should be able to provide information and develop principles of teaching respectively. Table 6 shows that 19 (38\%) participants believed developing the team in working place was the main skill of this type of nurse's role. A small number of responders highlighted that equality and diversity 10 $(20 \%)$ are the main clinical leadership skills of an ANP. Regarding perspectives of an ANP, table 7 shows that majority of participants 40 (80\%) suggested that ANP should be incorporate into context of health care including primary health care 
participants mentioned that governmental health policy is helpful to introduce ANP into health care sectors of Kurdistan region.

In other words, as is clarified in the table 7, most participants thought developing of ANP in Kurdistan region may be difficult due to deficiencies of job descriptions in the health care system (46\%) and lack of inter and intra professional cooperation 6 (12 \%) among health care staff at the hospitals. In addition, 4 (8\%) considered that socio-political environment of hospitals is another difficulty in front of introducing ANP in Kurdistan region.

Table 5: perspective of participants regarding facilitating-learning ANP competency domain.

\begin{tabular}{lcc|}
\hline Facilitating Learning & Frequency & $\%$ \\
\hline Principles of teaching and learning & 17 & 34 \\
Supporting others to develop knowledge and skills & 15 & 30 \\
Promotion of learning / creation of learning environment & 16 & 32 \\
Service user/ career teaching and information giving & 10 & 20 \\
Developing service user/ career education materials & 14 & 28 \\
Mentorship and coaching & & 30 \\
Building capability and capacity & 15 & 34 \\
\hline
\end{tabular}

Table 6: Perspective of participants about clinical leadership basic skills.

\begin{tabular}{lcc|}
\hline \multicolumn{1}{c}{ Clinical /Professional Leadership } & Frequency & $\%$ \\
\hline $\begin{array}{l}\text { Identifying need for change, developing case for change including service } \\
\text { development. }\end{array}$ & 16 & 32 \\
& & \\
Clinical Governance & 11 & 22 \\
Equality \& Diversity & 10 & 20 \\
Ethical decision-making & 16 & 32 \\
Developing case for change & 13 & 26 \\
Negotiation and influencing skills & 13 & 26 \\
Incorporate values-based care into practice & 12 & 24 \\
Networking & 13 & 26 \\
Team Development & 19 & 38
\end{tabular}


Table 7: Participant perspectives regarding incorporation of the ANPs in health care sectors and obstacles of introducing ANP into health care settings in KR

\begin{tabular}{|c|c|c|c|}
\hline & & Frequency & $\%$ \\
\hline Incorporation of the ANP into & Yes & 40 & 80 \\
\hline \multirow{2}{*}{ health settings } & No & 10 & 20 \\
\hline & Total & 50 & 100 \\
\hline \multirow{6}{*}{ Incorporate ANPs } & To meet the health needs of society & 23 & 46 \\
\hline & Health care work loads & 5 & 10 \\
\hline & Governmental policy and support & 3 & 6 \\
\hline & Development of nursing education & 15 & 30 \\
\hline & No answered & 4 & 8 \\
\hline & Total & 50 & 100 \\
\hline \multirow{8}{*}{$\begin{array}{l}\text { Obstacles of introducing of } \\
\text { ANP }\end{array}$} & & Frequency & (\%) \\
\hline & $\begin{array}{l}\text { Lack of Job description in the health care sys- } \\
\text { tem }\end{array}$ & 23 & 46 \\
\hline & Absence of the high qualified nurses & 5 & 10 \\
\hline & Socio-Political environment of the health agen- & 4 & 8 \\
\hline & cies & & \\
\hline & $\begin{array}{l}\text { Lack of inter-intra professional } \\
\text { tion's }\end{array}$ & 6 & 12 \\
\hline & No answered & 2 & 4 \\
\hline & Total & 50 & 100 \\
\hline
\end{tabular}

\section{DISCUSSION}

The present study found that most of the participants believed that holding a diploma certificate in nursing (those who graduate in technical institute) $(22 \%)$ is required to be appointed as an ANP, whereas $(20 \%)$ and (18 \%) of participants highlighted that M.Sc. and PhD are required for being an ANP respectively. As indicated in the literature, nurses working at advanced level during extensive clinical practice experience of a specific field and following completion of Master's level or above can work as ANPs. Various studies support having a Masters degree as the minimum to appointed as ANP [2, 5, 7].
This study has found that few participants had acceptable knowledge about the roles of ANP. It might be due to this role is not delineated in Iraq, and Kurdistan region. Most participants are not studying abroad specifically in United Kingdom (UK) and the United States or other countries where nurses have this role. In contrast to this study, for the first time in the UK a study found that an ANP must be an expert practitioner, educator, researcher and consultant in clinical practice [13]. Moreover, three studies have suggested that role of the ANP should not be introduced as a homogeneous category, however; it needs to be introduced as heterogeneous sub-roles $[5,10]$. With respect to characteristics and skills of ANP 
domains as shown in the table (2), participants of this study did not provide insight regarding competencies of ANP in terms of clinical performance, characteristics of clinical leadership and conducting research. This is might be due to two factors: there is no such kind of nursing roles in the Iraq and Kurdistan region and advanced nursing has not been incorporated into postgraduate curriculums. Numerous studies regarding ANP have stated that it must play the key roles in competencies of advanced nurse practitioner, being educator in clinical practice, researcher, leader and manger in clinical practice [18]. Most participants have diverse views regarding ANP sub-role competencies; this might be referred to lack of inadequate knowledge regarding this role. Incorporating ANPs into the health care system in the Kurdistan region is seen as essential by the participants in which $40(80 \%)$ supported that ANP should be introduced in health care system of KR. This is because all felt that role of nurses has to be expanded to improve the health care services and to meet patients' needs. Implementation of new roles might be confronted variety of challenges and problems. A total $46 \%$ expected that developing such kind roles in KR is likely to face a number of challenges including a lack of job description, supporting of professional bodies, and role recognition by authorities. Most participants supposed that lack of job description and lack of inter and intra-professional cooperation were the main obstacles [22]. Additional study with more participants, including all nurses who hold B.Sc. or High and Diploma in nursing, and medical doctors, and other stakeholders, should be conducted. The concept ANP need to be explained for nurses who hold M.Sc., PhD or both of them in order to provide an insight regarding ANP. Additionally,, it is important that the responsibility of APNs should be clarified for nurses at hospitals and other health care settings. Finally, it is

Recommended that a module of ANP have to in corporate into postgraduate curriculum in nursing faculties.

\section{CONCLUSION}

Inadequate knowledge regarding sub roles, competences of ANP, and required qualify cation to enter the level of ANP were identified. Participant attitudes toward developing ANPs in KR were positive. The role of ANP need to be more clearly defined to all postgraduate nurses in order to improve and meet health care needs in this region.

\section{CONFLICT OF INTEREST:}

There is no conflict of interest to declare regrading this study.

\section{FUNDING SOURCES:}

This research received no specific grant from any funding agency in the public, commercial, or not-for-profit sector

\section{REFERENCES:}

[1] Mantzoukas S, Watkinson S. Review of advanced nursing practice: the international literature and developing the generic features. J Clin Nurs. 2007;16(1):28-37

[2] Department of Health. Advanced level Nursing: A position statement. Leeds: UK Government; 2010

[3] Keane A, Becker D. Emerging Roles of the Advanced Practice Nurse. In: Joel AL (eds) Advanced practice nursing essentials for role development. Nursing, Joanne Patzek DaCunh. The 
United States of America. 2009. 23-45

[4] Ketefian $S$, Redman R, Hanucharurnkul S, Masterson A, Neves $E$. The development of advanced practice roles: implications in the international nursing community. Int Nurs Rev. 2001;48 (3):152-163

[5] Hamric A, Spross J, Hanson C, Hamric A. Advanced practice nursing. St. Louis: Elsevier Saunders; 2009.

[6] Schober M, Affara F. International Council of Nurses. Oxford, UK: Blackwell Pub; 2006.

[7] International Council of Nurses: The scope of practice, standards, and competencies of the advanced practice nurse. International Council of Nurses, Switzerland: ICN Regulation Series; 2008.

[8] Pearson A, Peels S. 1: Nursing - A Global Perspective. International Journal of Nursing Practice. 2001:7 (1): S1-S4.

[9] Dunn L. A literature review of advanced clinical nursing practice in the United States of America. Journal of Advanced Nursing. 1997:25(4):814 $-819$.

[10] Bryant-Lukosius D, DiCenso A. A framework for the introduction and evaluation of advanced practice nursing roles. Journal of Advanced Nursing. 2004: 8(5):530-540.

[11] Daly W, Carnwell R. Nursing roles and levels of practice: a framework for differentiating between elementary, specialist and advancing nursing practice. Journal of Clinical Nursing. 2003:12(2):158-167.

[12] Geest DM, Moons P, Callens P, Gut C, Lindpaintner L, Spirig R, Introducing advanced practice/nurse practitioners in health care systems / a framework for reflection and analysis. Swiss Med Wkly. 2008; 138 (43-44): 621-628
[13] Manley K. A conceptual framework for advanced practice: an action research project operationalizing an advanced practitioner/consultant nurse role. Journal of Clinical Nursing. 1997:6(3):179-190.

[14] Canadian Nurse Association, Advanced Nurse Practice: A national Framework [Internet]. 2008. Available from: https://www.cna-aiic.ca/-/media/ cna/page-content/pdf-en/ anp_national_framework_e.pdf [Accessed June, 2018]

[15] American Nurses Association. Nursing's social policy statement [Internet]. Washington, DC : United States of America. 1995. Available from: https:// essentialguidetonursingpractice.files.wordpress.com/2012/07/ pages-from-essential-guide-tonursing-practice-chapter-1.pdf [Accessed June, 2018]

[16] Pieper, B., \& Colwell, J. Doctoral education for WOC nurses considering advanced practice nursing. Journal of Wound Ostomy \& Continence Nursing, 2012. 39(3): 249 -255 .

[17] Mejza B. Will the WOC, Nurse of the Future Also Be a DNP. Journal of Wound, Ostomy and Continence Nursing. 2009:36(3):271-274.

[18] Davies B, Hughes A. Clarification of Advanced Nursing Practice: Characteristics and Competencies. Clinical Nurse Specialist. 2002:16 (3):147-152.

[19] National Prescribing Center. A single competency framework for all prescribers [Internet]. United Kingdom: National Institute for Health and Clinical Excellence [reviewed May 2014]. Available from: https:// www.associationforprescribers.org.u 
/images/

Single_Competency_Framework.pdf

[Accessed June, 2018]

[20] Joel L. Advanced practice nursing. Philadelphia: F.A. Davis; 2009.

[21] Advanced Nursing Practice Toolkit [Internet]. 2015 [cited 31 October 2015]. Available from: http:// www.advancedpractice.scot.nhs.uk

[22] Kleinpell R. Evolving Role Descriptions of the Acute Care Nurse Practitioner. Critical Care Nursing Quarterly. 1999:21(4):9-15. 